Supporting Information

\title{
Handedness Inversion in Chiral Nematic (Ethyl)cellulose Solutions: Effects of Substituents and Temperature
}

Yoshiyuki Nishio*, Takayuki Nada, Takuma Hirata, Shinpei Fujita, Kazuki Sugimura*, and Hiroshi

Kamitakahara

Division of Forest and Biomaterials Science, Graduate School of Agriculture, Kyoto University, Sakyo-ku, Kyoto 606-8502, Japan

*Corresponding author. E-mail address: kazusugi@,kais.kyoto-u.ac.jp (Dr. K. Sugimura); ynishio@kais.kyoto-u.ac.jp (Prof. Y. Nishio). Phone: +81 75753 6252. Fax: +81 757536300. 

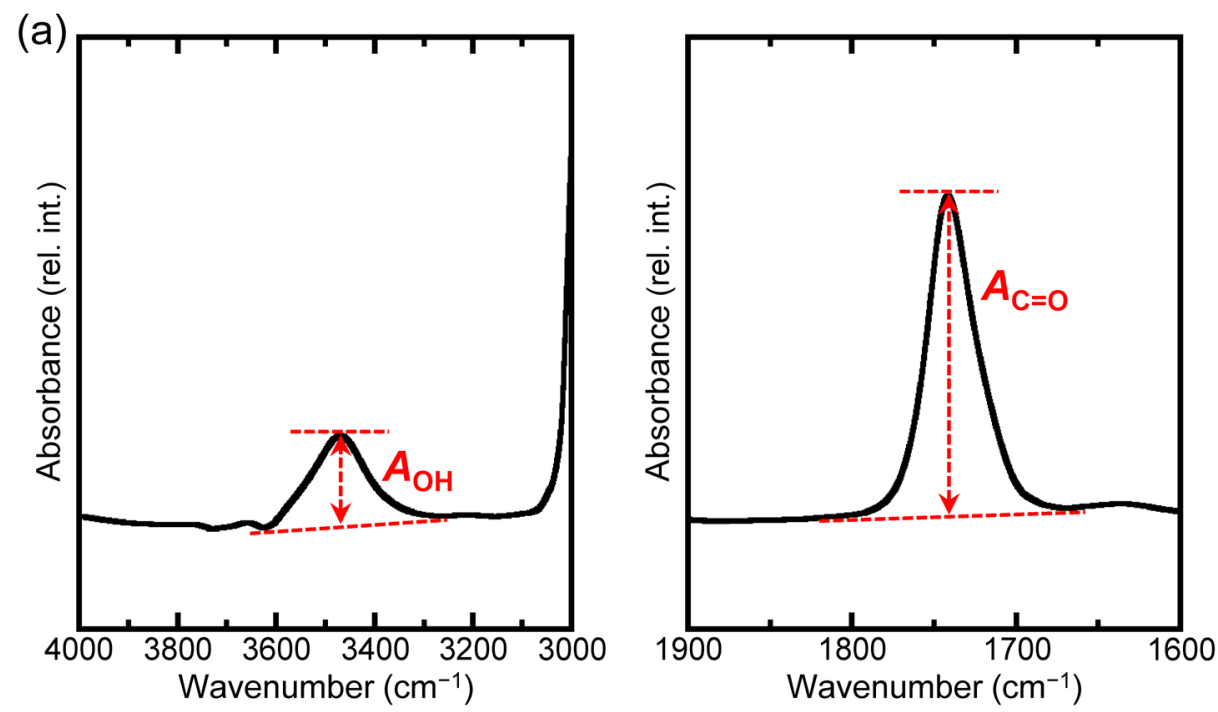

(b)

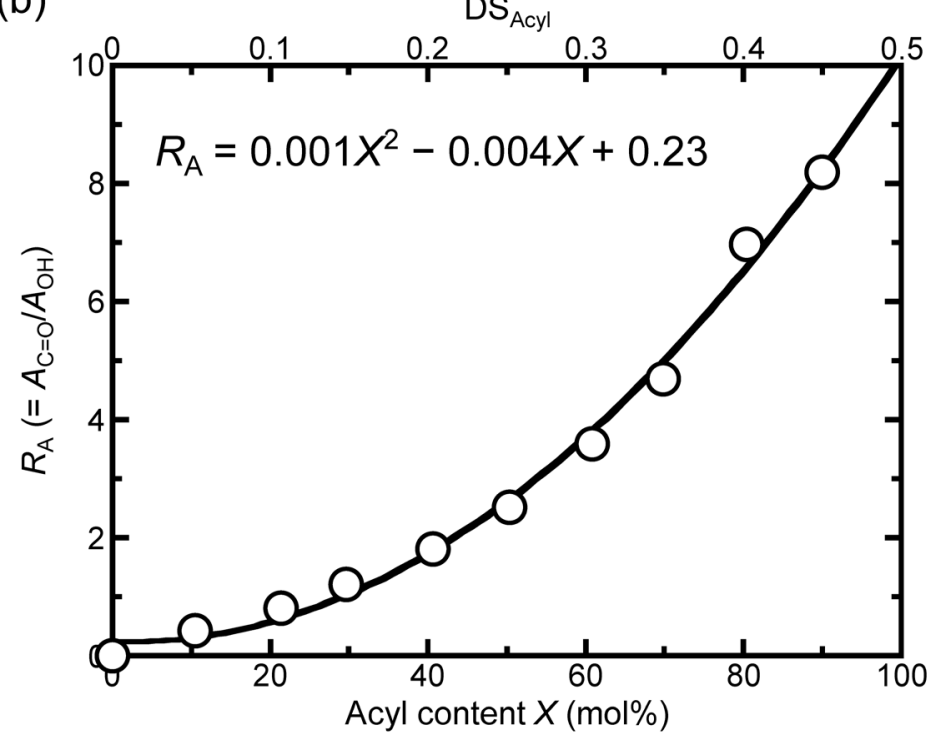

Figure S1. (a) FT-IR absorption signals, a hydroxyl peak (left, 3300-3640 $\mathrm{cm}^{-1}$ ) and a carbonyl peak (right, $1670-1830 \mathrm{~cm}^{-1}$ ), exemplified for a mixture of $\mathrm{EC} / \mathrm{A}-\mathrm{EC}_{0.50}(39: 61 \mathrm{in} \mathrm{mol} \%$ ), and (b) a calibration curve of $R_{\mathrm{A}}\left(=A_{\mathrm{C}=\mathrm{O}} / A_{\mathrm{OH}}\right)$ vs. \% acylation, constructed for determination of $\mathrm{DS}_{\mathrm{Acyl}}$ of EC acylates.

Notes: A fully acetylated EC $\left(\mathrm{A}-\mathrm{EC}_{0.50}\right)$ was synthesized by reference to a method adopted in earlier

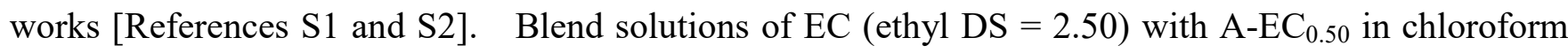
were prepared at a polymer concentration of $5 \mathrm{wt} \%$ in the desired proportions of $\mathrm{EC} / \mathrm{A}-\mathrm{EC}_{0.50}(10: 90$ to 90:10 in mol\%). FT-IR measurements were performed on the EC/A-EC $\mathrm{E}_{0.50}$ solutions (see Experimental Section in the main text). Part (a) of Figure S1 illustrates a set of two IR absorption signals, a hydroxyl peak (centered at $\sim 3480 \mathrm{~cm}^{-1}$ ) and a carbonyl peak (centered at $\sim 1740 \mathrm{~cm}^{-1}$ ), obtained for a mixture of $\mathrm{EC} / \mathrm{A}-\mathrm{EC}_{0.50}=39: 61$. Using the data of absorbance ratio $\left(R_{\mathrm{A}}=A_{\mathrm{C}=\mathrm{O}} / A_{\mathrm{OH}}\right)$ obtained for total nine mixtures, we constructed a calibration curve $\left(R_{\mathrm{A}}\right.$ vs. \% acylation) drawn in part (b) of Figure $\mathrm{S} 1$. 
Table S1. Visual Appearance of B-EC Lyotropics in $\mathrm{CHCl}_{3}, \mathrm{AA}$, and DCA, with Photographic Data Obtained through Digital Scanning of the Bottom of Each Sample Vial

\begin{tabular}{|c|c|c|c|c|c|c|c|c|c|c|c|}
\hline \multirow{2}{*}{ Solvent } & \multirow{2}{*}{$\begin{array}{l}\text { Temp. } \\
\left({ }^{\circ} \mathrm{C}\right)\end{array}$} & \multirow{2}{*}{$\begin{array}{l}\text { Polym. conc. } \\
\qquad(w t \%)\end{array}$} & \multicolumn{9}{|c|}{$\mathrm{DS}_{\text {Acyl }}$} \\
\hline & & & 0.09 & 0.13 & 0.20 & 0.24 & 0.27 & 0.34 & 0.39 & 0.45 & 0.50 \\
\hline $\mathrm{CHCl}_{3}$ & 5 & 40 & & & $x$ & $x$ & $x$ & $x$ & & & \\
\hline AA & 20 & 50 & $x$ & & & & & $x$ & $x$ & $x$ & $x$ \\
\hline DCA & 20 & 30 & $\mathrm{G}$ & $x$ & & & & & & & \\
\hline
\end{tabular}

Notations: $\times$, not colored; G, gelled.

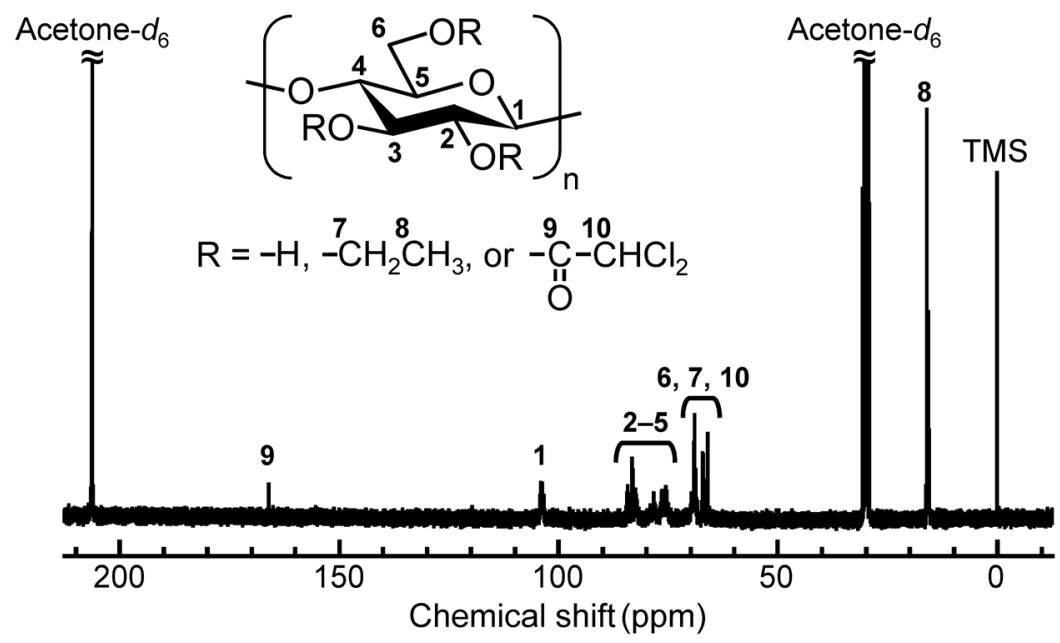

Figure S2. ${ }^{13} \mathrm{C}$ NMR spectrum of a DCA-treated EC sample (hereafter, termed Dca-EC) in acetone- $d_{6}$, the data indicating a chemical reaction of the residual hydroxyl groups of EC (ethyl DS $=2.50$ ) with the solvent DCA.

Notes: The DCA-treatment was conducted as follows: EC was dissolved in DCA at a polymer concentration of $10 \mathrm{wt} \%$ with stirring at $\sim 22{ }^{\circ} \mathrm{C}$ for 15 days. A light-yellowish product of Dca-EC was recovered from the EC/DCA solution via precipitation in $n$-hexane and subsequent washing with this solvent. The ${ }^{13} \mathrm{C}$ NMR spectrum was measured by using a Varian INOVA300 apparatus in the following conditions: temperature, $23{ }^{\circ} \mathrm{C}$; solute concentration, $30 \mathrm{mg} \mathrm{mL}{ }^{-1}$, internal standard, TMS; recycle time, $2 \mathrm{~s}$; number of scans, 20480. From the spectral data, it can be inferred that the residual $\mathrm{OH}$ groups partly reacted with DCA to yield an ester linkage, resulting in the appearance of carbonyl carbon at $\sim 165 \mathrm{ppm}$. 
(a)
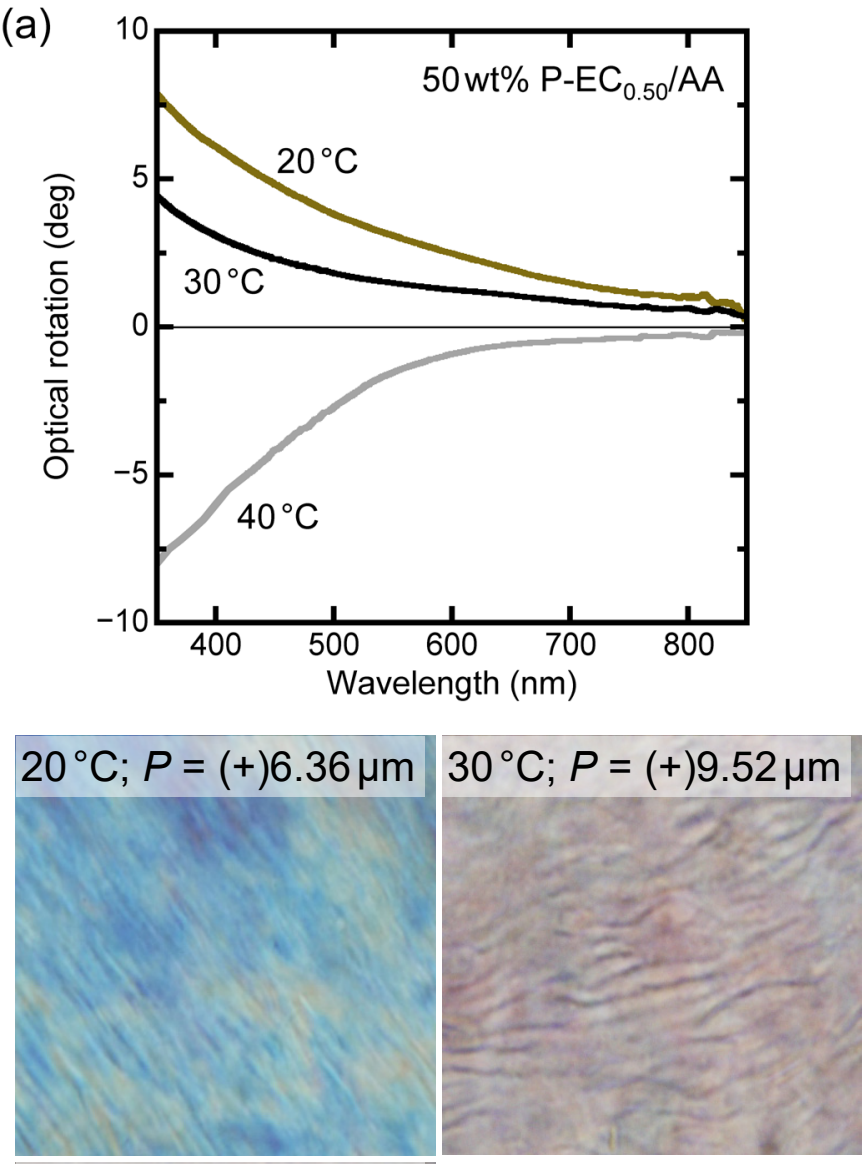

$40^{\circ} \mathrm{C} ; P=(-) 5.84 \mu \mathrm{m}$ (b)
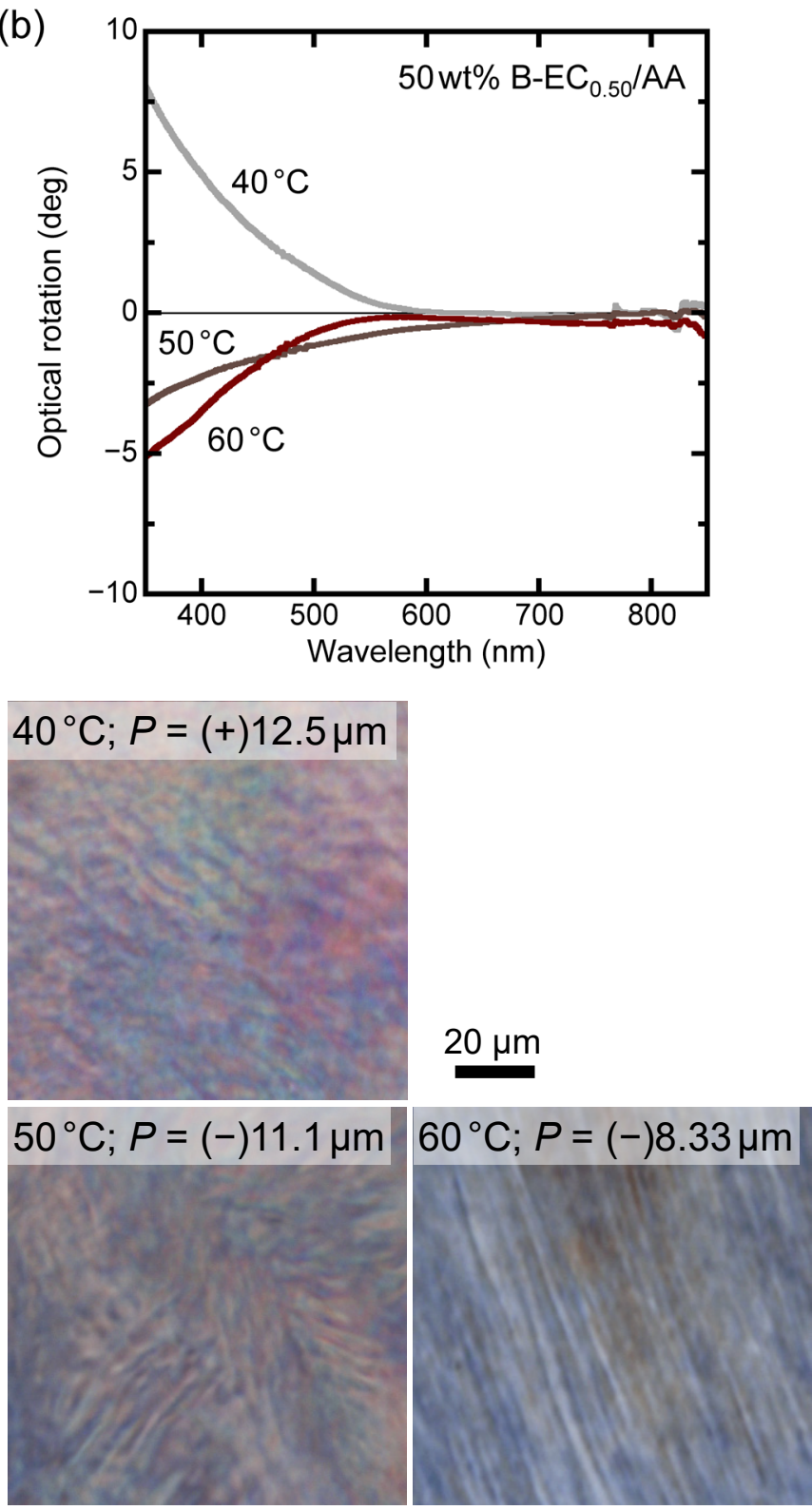

Figure S3. ORD (upper) and POM (lower) data obtained at different temperatures for lyotropic samples of (a) $50 \mathrm{wt} \% \mathrm{P}^{-E_{0}} \mathrm{C}_{0.5} / \mathrm{AA}$ and (b) $50 \mathrm{wt} \% \mathrm{~B}-\mathrm{EC}_{0.50} / \mathrm{AA}$, evidencing the thermally induced inversion of the chiral nematic twist sense $(P>0$, right-handed; $P<0$, left-handed).

\section{References}

[S1]: Guo, J. -X.; Gray, D. G. Preparation and liquid crystalline properties of (acetyl)(ethyl)cellulose, Macromolecules 1989, 22 (5), 2082-2086.

[S2]: Tezuka, Y.; Imai, K.; Oshima, M.; Chiba, T. Determination of substituent distribution in cellulose ethers by means of a ${ }^{13} \mathrm{C}$ NMR study on their acetylated derivatives. 1. Methylcellulose, Macromolecules 1987, 20 (10), 2413-2418. 